\title{
Erratum to: Symptom clusters during palliative chemotherapy and their influence on functioning and quality of life
}

\author{
Sun Young Rha ${ }^{1,2,3}$. Jiyeon Lee ${ }^{4}$
}

Published online: 11 April 2017

(C) Springer-Verlag Berlin Heidelberg 2017

Erratum to: Support Care Cancer

DOI 10.1007/s00520-016-3545-Z

Unfortunately, the original version of this article contained an error. The correct Fig. 1 is presented below.

The online version of the original article can be found at doi: http://dx.doi. org/10.1007/s00520-016-3545-z

\footnotetext{
Jiyeon Lee

Jiyeon.Lee@cnu.ac.kr; Jiyeonest@hotmail.com

1 College of Medicine and Songdang Institute for Cancer Research, Yonsei University, Seoul, South Korea

2 Yonsei Cancer Center, Seoul, South Korea

3 Brain Korea 21 Project for Medical Sciences, Seoul, South Korea

4 College of Nursing, Chungnam National University, Daejeon, South Korea
} 


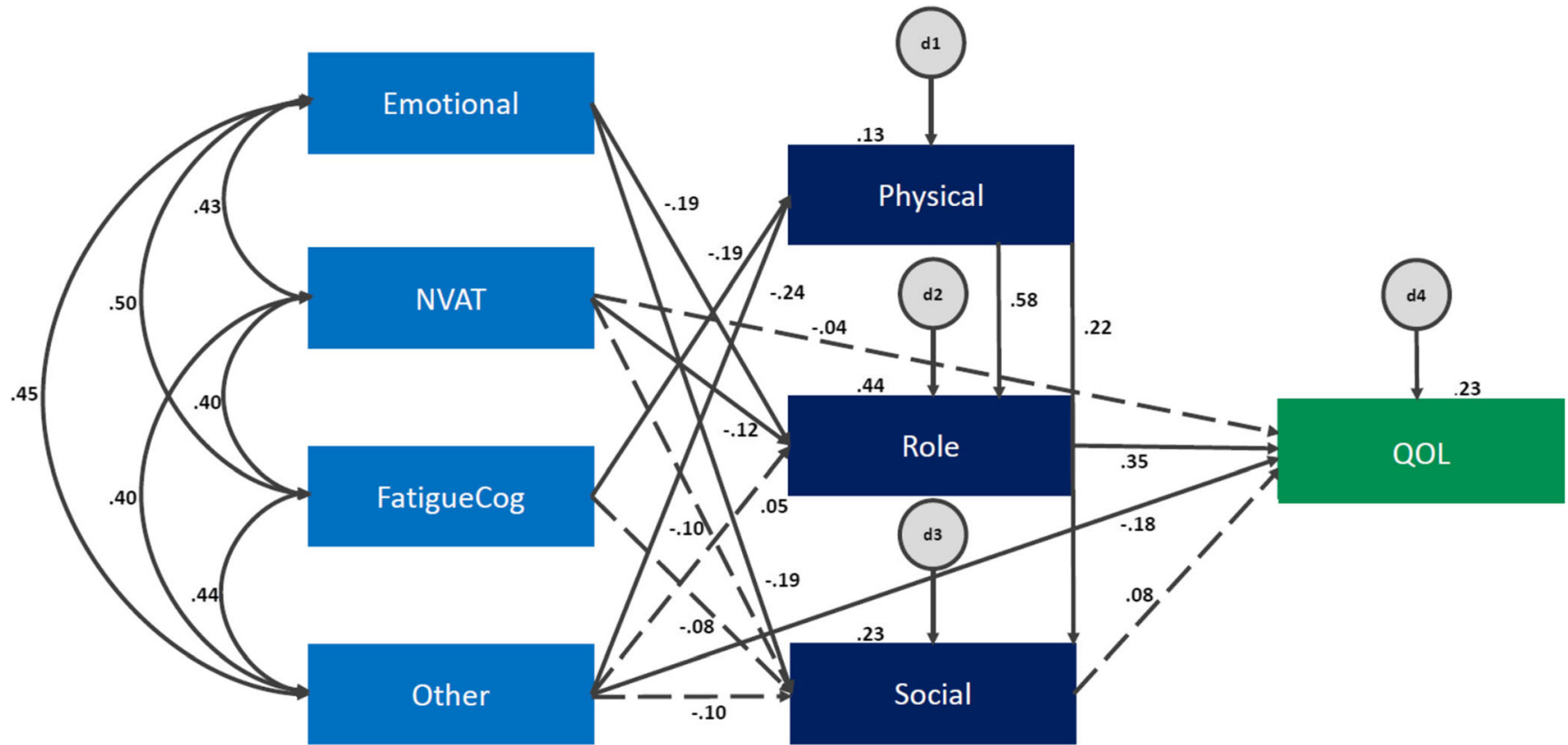

Fig. 1 Structural Equation Model for Symptom Clusters, Functioning and QOL. Emotional emotional cluster, NVAT nausea and vomiting/ appetite loss/taste change cluster, FatigueCog fatigue/cognitive cluster, Other other cluster, Physical physical functioning, Role role functioning,

effect of all other factors influencing the variable) of physical functioning, $d 2$ disturbance of role functioning, $d 3$ disturbance of social functioning, $d 4$ disturbance of QOL. Non-significant relationships are illustrated with dashed lines 